\title{
Exploring role of wine label adopting the neuromarketing method
}

\author{
Andrea Ciceri \\ andrea.ciceri@sensecatch.com \\ SenseCatch, Como, Italy \\ Giulia Songa \\ giulia.songa@sensecatch.com \\ SenseCatch, Como, Italy
}

\section{Background}

The research has examined the decision-making process of wine, focusing in particular on the role that labelling has. On the one hand, it was decided to take wine as object of study, as it is characterized by a high perception of risk. Purchase decision about this product could be considered as more complex than other products (Lockin, 2001) On the other hand, the focus has been restricted to wine labelling only, since it is an element that has a peculiar and fundamental role in the decision-making process of wine product. Packaging and labelling are the wine first line of communication (Charters et al, 2000). Wine bottles with pleasing aesthetic labelling solutions are in fact more likely to be chosen, a greater willingness to pay and a greater propensity to purchase (Barber et al., 2007; Boudreaux and Palmer, 2007).

\section{Research gap}

The study starts from a research gap. Up to now, research on wine in general and its labelling has adopted traditional research methods such as self-reports or questionnaires, which the research itself has highlighted its limit to analyze only the rational and conscious part of the decisionmaking processes.

Starting from this premise, the approach that was used in this research combined the classical research methodologies with the neuromarketing methodology, thus allowing to explore the irrational and emotional aspects of wine decision making. According to Plassman (Plassman et.al., 2012), neuromarketing combines neuroscience and psychophysiology with economics, marketing and behavioural psychology. The great innovation that neuromarketing brings to the method of conducting research and formulating marketing strategies is derived from the use of specific technologies, some of which have a neuroscientific matrix, such as electroencephalography, which give direct access to cognitive and emotional dimensions. Since these dimensions are subconscious, they cannot be investigated using techniques based on verbalization, such as those used by traditional market research which has always used focus groups, interviews or questionnaires. When we ask consumers for their opinion on a product or service, the answers we get come with typical distortions, due to our limited awareness and ability to express emotions, attitudes and experiences. Moreover, there is a tendency to provide "socially desirable" responses, i.e. tailored to what people feel the interviewer wants to hear or what they think will give a better impression of them. 
One of the main advantages of neuromarketing, therefore, relates to the possibility of accessing information which is difficult to obtain with traditional research methods. Neuromarketing method uses different neuroscientific tools to analyze biological signals to evaluate physiological feedback to communicative and experiental stimuli. It is considered a cutting-edge approach to analyze decision-making processes in which irrational, intuitive, heuristic, and affective processes play a key role (Stasi et. Al., 2018; Dijksterhuijs, 2004; Hassin, Uleman, \& Bargh, 2005; Ohme et al., 2009; Sayegh, Anthony, \& Perrewé, 2004).

\section{Objective}

The research has the aim on one side to better explore the role of wine labelling attribute in consumers' purchasing choice adopting an innovative and scientific approach able to explore the irrational and emotional factors at the basis of wine choice. In particular we investigated the effect of different kinds of papers and embellishments used for the wine labels on consumers' perceptions and purchase decisions. We explore the role of two senses: sight and touch, and how different kind of papers and embellishments were able to influence these senses contributing to the final choice.

On the other side this research aims to help develop an innovative and more reliable research approach in the wine decision-making process.

\section{Method}

Thirty labels were created combining six types of papers and six types of embellishments. Thirty bottles were displayed on the shelf. Thirty participants explored the shelf, first without any specific tasks, and then with the goal to choose a bottle of wine, while their visual behaviour were recorded using a portable eye-tracker. Eye-Tracker is a specific technology that measures the eye movements, determining precisely where the users' attention is oriented. It allows to identify where persons are looking objectively and with high temporal and spatial information accuracy (Chae \& Lee, 2013; Duchowski, 2003; Zurawicki, 2010).

The Eye-Tracking method is based on the "eye-mind" hypothesis, which affirms that what individuals are looking at reflects the cognitive activities happening in their minds (Hoffman, 1998) and for this reason is a data absolutely robust. Then, the participants were exposed to each single bottle. They had to watch each bottle for 15 seconds and then to handle it for the same amount of time. During this phase their visual behaviour and their brain activation were recorded. To collect the brain activation, participants wore an EEG headset. The EEG measures the cortical activation of consumers detecting the cortical electrical activity using electrodes placed on the scalp according to the International System (SI) 10-20 (Cacioppo, Tassinary, \& Berntson, 2000). At the end, an in-depth interview was conducted to assess the intention to purchase and the willingness to pay for the wine bottles.

\section{Results}

Results evidenced a specific role of paper and embellishment in the decision-making process. In terms of visual attention, labels uncoated, textured and black collected $83 \%$ of visual attention in the first 5 seconds. Considering the same exposure time, we also found a significative effect of embellishments. Gold embellishment was the kind of embellishment more able to catch the attention in comparison to the other 6 kind of embellishments. The same results have been demonstrated even in the first 20 seconds. We found a correlation between visual attention performance and choice. In particular the paper uncoated, textured and black was the paper more able to finalize the choice with $71 \%$ of times chosen. 
In terms of emotional engagement collected with EEG analysis, Rough Cotton and Velmart Black papers elicited the higher level, respectively 0.76 and 0.73 on a scale from 0 to 1 . Gloss, Liquid Gold and Relief embellishments contributed instead to generate a higher emotional engagement.

About intention to purchase black, matte and textured paper is the favorite both in terms of sight and touch. In particular has been demonstrated that when participants have the opportunity to touch the label, the intention to purchase increases by an additional $8 \%$ on average. Moreover, we found that hot foil embellishment was able to valorize the Cotton and the Velmart papers. In fact, this combination has been able to enhance the emotional engagement and increased consumers' willingness to pay.

\section{Conclusion}

During the "first moment of truth", i.e. when seeing the labels on the shelf, the first moment of contact with it, in which the ability of the label to be noticed is fundamental, the element most able to influence the visual attention (in terms of visual equity and visual saliency) is the type of paper. Matte, dark and textured paper captures the attention immediately and holds it for a long time. As far as selection of a bottle from the shelf is concerned, there is a relevant effect both from the type of paper, in favour of dark, matte and textured paper, and from the finish (in particular, the gold, glossy and embossed finish is the one most able to guide selection). During the "second moment of truth", i.e. interaction with the label, the paper has a significant influence on the level of emotional involvement, on the perception of the label and consequently on the intention to purchase. In fact, more textured types of paper lead to a stronger engagement and a higher intention to purchase.

Embellishments particularly pleasing to the touch improve the overall perception of the product and increase the intention to purchase. There is also an effect of mutual support between combinations of paper and embellishment, with a positive influence on the emotional involvement of the sensory contrast (especially tactile) conferred by the paper and the finish of the label. Textured labels combined with glossy finishes, especially if embossed, foster the perception of the wine as "luxury" and increase the price that the consumer is willing to pay.

Acknowledgments. This research has been promoted by UPM Raflatac, scientifically designed and managed by SenseCatch in partnership with Rotas, Luxoro, O'nice Design. Thanks to CIELO e TERRA Vini for providing the wine bottles.

\section{References}

[1] Barber, N., Ismail, J., \& Taylor, D. (2007). Label fluency and consumer self confidence. Journal of Wine Research, 18, 73-85

[2] Boudreaux, C.A., \& Palmer, S. (2007). A charming little cabernet: effects of wine label design on purchase intent and brand personality. International Journal of Wine Business Research, $19,170-186$

[3] Cacioppo, J. T., Tassinary, L. G., \& Berntson, G. G. (2000). Handbook of psychophysiology (2nd edition). New York: Cambridge University Press.

[4] Chae, S. W., \& Lee, K. C. (2013). Exploring the effect of the human brand on consumers' decision quality in online shopping: An eye-tracking approach. Online Information Review, $37,83-100$. 
[5] Charters, S., Lockshin, L., Unwin, T., (2000). Consumer responses to wine bottle back labels, The Australian and New Zealand Wine Industry Journal of Oenology, Viticulture, Finance \& Marketing, 15(3), 94-101

[6] Ciceri A., Russo V., Songa G., Gabrielli G., Clement J., (2019). A Neuroscientific Method for Assessing Effectiveness of Digital vs. Print Ads Using Biometric Techniques to Measure Cross-Media Ad Experience and Recall, Journal of Advertising Research.

[7] Dijksterhuijs, A. (2004). Think different: The merits of unconscious thought in preference development and decision making. Journal of Personality and Social Psychology, 87(5), 586-598.

[8] Duchowski, A. T. (2003). Eye tracking methodology: Theory and practice. New York, NY: Springer.

[9] Hassin, R. R., Uleman, J. S., \& Bargh, J. A. (2005). The new unconscious. New York: Oxford University Press.

[10] Hoffman, J. E. (1998). Visual attention and eye movements. In H. Pashler (Ed.). Attention. London: University College London Press.

[11] Lockshin, L., \& Corsi, A.M. (2012). Consumer behaviour for wine 2.0: A review since 2003 and future directions. Wine Economics and Policy, 1(1), 2-23

[12] Ohme, R., Reykowska, D., Wiener, D., \& Choromanska, A. (2009). Analysis of neurophysiological reactions to advertising stimuli by means of EEG and galvanic skin response measures. Journal of Neuroscience, Psychology, and Economics, 2(1), 21-31.

[13] Plassmann, H., Ramsøy, T. Z., \& Milosavljevic, M. (2012). Branding the brain: A critical review and outlook. Journal of Consumer Psychology, 22(1), 18-36.

[14] Sayegh, L., Anthony, W. P., \& Perrewé, P. L. (2004). Managerial decision-making under crisis: The role of emotion in an intuitive decision process. Human Resource Management Review, 14(2), 179-199.

[15] Stasi A., G. Songa, M. Mauri, A. Ciceri, F. Diotallevi, G. Nardone, V. Russo, Neuromarketing empirical approaches and food choice: A systematic review, Food Research International, Volume 108, 2018, 650-664.

[16] Zurawicki, L. (2010). Neuromarketing exploring the brain of the consumer. New York: Springer. 